\title{
Association between Charlson comorbidity index and complications of endoscopic resection of gastric neoplasms in elderly patients
}

Sunmin $\mathrm{Kim}^{\dagger}$, Dong Hyun Kim${ }^{\dagger}$, Seon-Young Park, Chang Hwan Park, Hyun Soo Kim, Sung Kyu Choi and Jong Sun Rew

\begin{abstract}
Background: Although endoscopic resection is safe and effective for gastric epithelial neoplasms, information is limited on its efficacy and safety in extremely elderly patients who have various comorbidities. Further, the relationship between comorbidities and complications of endoscopic resection is not well established. Therefore, we aimed to evaluate the efficacy and safety of endoscopic resection of gastric epithelial neoplasms in extremely elderly patients.

Methods: From October 2008 to December 2017, 4475 consecutive patients underwent endoscopic resection of gastric epithelial neoplasms. Among them, 242 were 75 years or older. We assessed Charlson comorbidity index (CCI) scores, procedural outcomes, and procedure- and sedation-related complications related to endoscopic resection.

Results: Mean patient age was $78.7 \pm 3.2$ years. Of the 242 patients, 124 (51.2\%) had low-grade dysplasia and 112 (46.3\%) had adenocarcinoma. The most common comorbidity was hypertension (55.4\%), followed by diabetes (23.1\%). The mean CCl score was $1.67 \pm 1.43$. Sixty patients (24.8\%) had a CCl score $\geq 3$. During the procedure, 10 (4.1\%) patients had desaturation that recovered by flumazenil use with mask $(n=2)$ or Ambu bag $(n=3)$ ventilation. During subsequent admission, atelectasis or pneumonia occurred in 45 (18.6\%) patients, post-procedural bleeding in $12(5.0 \%)$, and perforation in $3(1.2 \%)$. Respiratory complications were more common in patients with a CCl score $\geq 3(20 / 60,33.3 \%)$ than in those with a CCl score $<3(25 / 182,13.7 \%, P=0.002)$.

Conclusions: $\mathrm{CCl}$ score is related to respiratory complications of endoscopic resection in extremely elderly patients. Endoscopic resection must be performed cautiously, particularly in elderly patients with a high CCl score, to prevent respiratory complications.
\end{abstract}

Keywords: Endoscopic mucosal resection, Aged, Comorbidity, Stomach neoplasms

\footnotetext{
*Correspondence: drpsy@naver.com

†Sunmin Kim and Dong Hyun Kim contributed equally to this work. Division of Gastroenterology and Hepatology, Department of Internal Medicine, Chonnam National Medical School, Gwangju, South Korea
}

(c) The Author(s). 2020 Open Access This article is licensed under a Creative Commons Attribution 4.0 International License, which permits use, sharing, adaptation, distribution and reproduction in any medium or format, as long as you give appropriate credit to the original author(s) and the source, provide a link to the Creative Commons licence, and indicate if changes were made. The images or other third party material in this article are included in the article's Creative Commons licence, unless indicated otherwise in a credit line to the material. If material is not included in the article's Creative Commons licence and your intended use is not permitted by statutory regulation or exceeds the permitted use, you will need to obtain permission directly from the copyright holder. To view a copy of this licence, visit http://creativecommons.org/licenses/by/4.0/ The Creative Commons Public Domain Dedication waiver (http://creativecommons.org/publicdomain/zero/1.0/) applies to the data made available in this article, unless otherwise stated in a credit line to the data. 


\section{Background}

Endoscopic resection is safe and effective for the treatment of gastric epithelial neoplasms and has a low risk of procedure-related complications [1-3]. In increasingly aged societies, a growing number of endoscopic treatments are performed for the elderly, and several reports have shown contrasting treatment outcomes and complications of endoscopic resection in elderly and nonelderly patients [4-8].

Elderly patients, especially those aged 75 years or older (extremely elderly patients), have various comorbidities and functional disabilities that influence daily life $[9,10]$. Although several studies have reported that endoscopic mucosal resection (EMR) and endoscopic submucosal dissection (ESD) are safe and reliable in the elderly [4-8], endoscopy itself carries risks in elderly patients, particularly those with renal or respiratory comorbidities [11, 12].

In the real-world clinical setting, endoscopists must consider comorbidities, performance status (PS), and expected survival in elderly patients. The relationship between comorbidities and complications of endoscopic resection in elderly patients is not well established. The Charlson comorbidity index (CCI) has been widely utilized to measure the burden of complex comorbidities by health researchers [13]. The CCI predicts mortality by classifying or weighting comorbidities and has been validated in various disease subgroups, including stroke, cardiac disease, renal disease, and liver disease [14-17]. However, no studies to date have examined the relationship between CCI score and incidence of complications after endoscopic resection of gastric epithelial neoplasms in elderly patients.

Here we aimed to evaluate the CCI and efficacy and safety of endoscopic resection of gastric epithelial neoplasms in extremely elderly patients.

\section{Methods}

\section{Study population}

This retrospective study was conducted in accordance with the Ethical Guidelines of the Declaration of Helsinki. This study was approved by the Institutional Review Board of Chonnam National University Hospital (no. CNUH-2018-236).

From October 2008 to December 2017, a total of 4475 consecutive patients underwent endoscopic resection of gastric epithelial neoplasms in our center. Among them, 242 aged 75 years or older were included in this study. The patients underwent ESD or EMR for gastric epithelial neoplasms. We reviewed their medical records and extracted information about their demographic and clinical characteristics, procedural outcomes, and procedure- or sedation-related complications.
Assessment of $\mathrm{CCl}$ scores before endoscopic procedure The components of CCI include: previous myocardial infarction, congestive cardiac failure, peripheral vascular disease, cerebrovascular accident, dementia, chronic obstructive pulmonary disease, connective tissue disease, peptic ulcer disease, diabetes, renal disease, hemiplegia, leukemia, lymphoma, solid tumor with or without metastatic disease, liver disease, and acquired immunodeficiency syndrome status. We calculated the $\mathrm{CCI}$ by summing the weights of all comorbid parameters. The total CCI score was $0-33$. We divided the patients into those with a $\mathrm{CCI}<3$ and those with a $\mathrm{CCI} \geq 3$.

\section{Performance status}

We reviewed the patients' medical records to investigate their social history, body mass index, and comorbidities. Based on these data, the performance status of all enrolled patients was evaluated using the American Society of Anesthesiologists-Performance Status and Eastern Cooperative Oncology Group-Performance Status.

\section{Endoscopic procedure}

Endoscopists determined the methods of removal for the lesions (EMR or ESD) according to shape, size, presence of fibrosis, or presence of lesion ulceration before endoscopic resection. For ESD or EMR, patients were placed in the left lateral decubitus position. Each endoscopic procedure was performed using a single-channel upper gastrointestinal endoscope with transparent hood under $\mathrm{CO}_{2}$ insufflation.

\section{Anticoagulants or antiplatelet agents}

Anticoagulant and antiplatelet agent therapy was discontinued for endoscopic resection according to the recommended cessation period [18]. The endoscopic procedure was evaluated as a high risk procedure that could cause bleeding, and the discontinuation of the drug was determined individually according to the patient's pre-existing thromboembolic condition.

\section{Anesthesia procedure}

All procedures were performed with use of endoscopistdirected sedation. Patients were sedated with midazolam and pethidine with or without propofol. The target sedation level was mild to moderate [19]. For sedation induction, midazolam $3 \mathrm{mg}$ and pethidine $25 \mathrm{mg}$ were intravenously injected. Thereafter, additional propofol, midazolam, or pethidine was intravenously injected to ensure adequate sedation or pain control. Oxygen was supplied at a constant level of $2 \mathrm{~L} / \mathrm{min}$ via a nasal prong during the procedure, and sedative medication doses were adjusted according to the vital signs of patients. We monitored blood pressure, heart rate, and oxygen saturation during the procedure. 


\section{Outcome measures}

The primary outcome was procedure- and sedationrelated complications, while the secondary outcomes were procedure time and complete resection rate.

\section{Procedure-related complications}

Procedure-related bleeding was defined as bleeding requiring transfusion or emergency endoscopy or that reduced the hemoglobin level by more than $2 \mathrm{~g} / \mathrm{dL}$ following the procedure. We defined immediate bleeding as bleeding occurring within $24 \mathrm{~h}$ after the endoscopic resection and delayed bleeding as gastrointestinal bleeding occurring later than $24 \mathrm{~h}$ after the endoscopic resection [20, 21]. Procedure-related perforation was defined as endoscopically observed extraluminal space or intraabdominal free air on chest radiography taken after the procedure [21].

\section{Sedation-related complications}

Sedation-related complications were divided into immediate complications (hypotension, arrhythmia, hypoxia) during endoscopy and post-procedural complications (respiratory complications such as atelectasis and pneumonia).

Hypotension during the procedure was defined as systolic blood pressure below $90 \mathrm{mmHg}$. Oxygen desaturation was defined as oxygen arterial saturation $<90 \%$ for at least $10 \mathrm{~s}$. Supplemental oxygen was given to maintain oxygen arterial saturation $>90 \%$. Bradycardia was defined as any episode of heart rate $<40$ beats per minute.

All patients underwent pre-procedure chest radiography at the time of admission. Atelectasis was diagnosed by comparison of post-procedure and preprocedure chest radiographic findings, regardless of clinical symptoms. Radiographic findings of atelectasis include direct signs such as crowding of pulmonary vessels, crowed air bronchogram, and displacement of interlobar fissure as well as indirect signs such as pulmonary opacification and elevation of the ipsilateral diaphragm. Pneumonia was defined as newly developed pulmonary infiltration with clinical symptoms such as cough, sputum, and fever with chilling. In these cases, proper antibiotics were administered.

\section{Procedure time}

Procedure time was defined as the time from the start of intravenous administration of the sedative agent to the time of endoscope extubation.

\section{Complete resection}

Complete resection was defined as follows: 1) tumor removed in one piece (en bloc resection) and horizontal/ vertical margin was histologically free from tumorous glands; or 2) tumor removed in multiple pieces (piecemeal resection) and follow-up endoscopy revealed no recurrence for at least 1 year.

\section{Follow up endoscopy}

Follow-up endoscopy was performed 3-6 months after endoscopic resection, and follow-up endoscopy was performed every year thereafter. We defined tumor recurrence as local recurred or metachronous lesions in the stomach after 1 year after endoscopic resection of the primary lesion.

\section{Statistical analysis}

Statistical analysis was performed using SPSS version 23.0 (SPSS Inc., Chicago, IL, USA). Continuous data are shown as mean \pm standard deviation or median (range), while categorical data are shown as absolute and relative frequencies. Continuous variables were analyzed using Student's t-test. Categorical data were examined using Fisher's exact test or the chi-squared test. On multivariate analysis, binary logistic regression models with forward conditioning were used to investigate CCIassociated complications. The data included in the regression analysis are presented as crude or adjusted odds ratios with 95\% confidence intervals (CIs). Variables with $P$ values $<0.05$ on the univariate analysis were selected for inclusion in the multivariate analysis.

\section{Results \\ Patient demographics}

The mean patient age was $78.7 \pm 3.2$ years. Of the 242 patients, 124 (51.2\%) had low-grade dysplasia and 112 (46.3\%) had carcinoma in situ or adenocarcinoma (Table 1). The most common comorbidity was hypertension (55.4\%), followed by diabetes (23.1\%) (Table 2). A total of 141 (58.3\%) patients underwent ESD. Seventy-one (31\%) patients underwent endoscopic resection of multiple lesions in a single session. The mean procedure time was $34.9 \pm$ $23.7 \mathrm{~min}$, and the mean hospital stay was $5.0 \pm 1.7$ days. Midazolam was used in all patients and propofol was used in $215(88.8 \%)$ patients.

\section{Charlson comorbidity index}

The mean CCI score was $1.67 \pm 1.43$ (range, $0-7$ ). Figure 1 shows the distribution of the CCI score in the 242 patients: $59(24.4 \%)$ had a CCI score of 0, 65 (26.9\%) had a CCI score of $1,58(24.0 \%)$ had a CCI score of $2,29(12.0 \%)$ had a CCI score of 3, $23(9.5 \%)$ had a CCI score of $4,6(2.5 \%)$ had a CCI score of $5,1(0.4 \%)$ had a CCI score of 6 , and $1(0.4 \%)$ had a CCI score of 7 . Thus, 182 patients had a low CCI score $(<3)$ and 60 had a high CCI score $(\geq 3)$.

\section{Procedure-related complications}

Procedure-related complications included immediate bleeding (4.1\%), delayed bleeding $(0.8 \%)$ and perforation 
Table 1 Endoscopic and histologic findings in 242 elderly patients

\begin{tabular}{|c|c|}
\hline Variables & \\
\hline \multicolumn{2}{|l|}{ Number of lesions, $n(\%)$} \\
\hline Single & $166(68.6)$ \\
\hline Multiple & $76(31.4)$ \\
\hline \multicolumn{2}{|l|}{ Location of lesion, $n(\%)$} \\
\hline Upper $1 / 3$ & $28(11.5)$ \\
\hline Mid 1/3 & $78(32.2)$ \\
\hline Lower $1 / 3$ & $136(56.2)$ \\
\hline \multicolumn{2}{|l|}{ Macroscopic appearance, $n$ (\%) } \\
\hline Flat/depressed & $67(27.7)$ \\
\hline Elevated & $175(72.3)$ \\
\hline \multicolumn{2}{|l|}{ Histologic findings, $n(\%)$} \\
\hline Low-grade dysplasia & $124(51.2)$ \\
\hline Carcinoma in situ or adenocarcinoma & $112(46.3)$ \\
\hline Other & $6(2.5)$ \\
\hline \multicolumn{2}{|l|}{ Method of endoscopic resection, $n(\%)$} \\
\hline EMR & $100(41.3)$ \\
\hline ESD & $142(58.7)$ \\
\hline Mean procedure time, min, mean \pm SD & $34.9 \pm 23.7$ \\
\hline \multicolumn{2}{|l|}{ Method of Sedation } \\
\hline Midazolam + Propofol+ Pethidine & $215(88.8)$ \\
\hline Midazolam + Pethidine & $27(11.2)$ \\
\hline \multicolumn{2}{|l|}{ Dose of sedative agents, mean \pm SD } \\
\hline Midazolam, mg & $3.43 \pm 1.16$ \\
\hline Propofol, mg & $112.0 \pm 88.0$ \\
\hline
\end{tabular}

$E M R$ endoscopic mucosal resection, $E S D$ endoscopic submucosal dissection, $S D$ standard deviation

(1.2\%). There were no significant differences in procedure-related complications between the low and high CCI groups.

\section{Sedation-related complications}

During the procedure, there were $10(4.1 \%)$ patients with desaturation recovered by flumazenil with use mask $(n=$ $2)$ or Ambu bag $(n=3)$ ventilation. No patient received endotracheal intubation during endoscopic procedure. There were no significant differences in the incidence of hypotension or hypoxia during the procedure between the low and high CCI groups.

Post-procedural complications such as atelectasis or pneumonia occurred in $45(18.6 \%)$ patients. In 4 patients, pneumonia was diagnosed due to fever, respiratory symptoms, and chest radiography abnormalities. These patients were treated with antibiotics and improved without sequelae. Most other patients improved spontaneously during the outpatient follow-up period (Fig. 2).
Table 2 Baseline characteristics and comorbidities of elderly patients who underwent endoscopic resection

\begin{tabular}{|c|c|c|}
\hline Variables & & \\
\hline Age, yrs., mean $\pm S D$ & & $78.7 \pm 3.2$ \\
\hline Female sex, $n(\%)$ & & $101(41.7)$ \\
\hline Body mass index, $\mathrm{kg} / \mathrm{m}^{2}$, mean $\pm \mathrm{SD}$ & & $23.7 \pm 3.3$ \\
\hline Comorbidities, variable CCI, n (\%) & Weighting & \\
\hline Acute myocardial infarction & 1 & $30(12.4)$ \\
\hline Congestive heart failure & 1 & $11(4.5)$ \\
\hline Peripheral vascular disease & 1 & $3(1.2)$ \\
\hline Cerebrovascular accident & 1 & $11(4.5)$ \\
\hline Dementia & 1 & $5(2.1)$ \\
\hline Chronic pulmonary disease & 1 & $27(11.2)$ \\
\hline Connective tissue disease & 1 & $0(0)$ \\
\hline Ulcer disease & 1 & $0(0)$ \\
\hline Mild liver disease & 1 & $13(5.4)$ \\
\hline Hepatitis & & $8(3.3)$ \\
\hline Diabetes & 1 & $56(23.1)$ \\
\hline Diabetes with end organ damage & 2 & $0(0)$ \\
\hline Hemiplegia & 2 & $0(0)$ \\
\hline Moderate or severe renal disease & 2 & $3(1.2)$ \\
\hline Any tumor & 2 & $31(12.8)$ \\
\hline Leukemia & 2 & $0(0)$ \\
\hline Lymphoma & 2 & $0(0)$ \\
\hline Moderate to severe liver disease & 3 & $5(2.1)$ \\
\hline Metastatic solid tumor & 6 & $0(0)$ \\
\hline Acquired immunodeficiency syndrome & 6 & $0(0)$ \\
\hline Charlson comorbidity index, mean \pm SD & & $1.67 \pm 1.43$ \\
\hline ASA-PS, mean \pm SD & & $2.01 \pm 0.49$ \\
\hline ECOG-PS, mean \pm SD & & $1.55 \pm 0.55$ \\
\hline \multicolumn{3}{|l|}{ Medication, $n(\%)$} \\
\hline Aspirin & & $70(28.9)$ \\
\hline Clopidogrel & & $10(4.1)$ \\
\hline Antithrombotic agents & & $1(0.4)$ \\
\hline
\end{tabular}

SD standard deviation, ASA-PS American Society of Anesthesiologists Performance Status, CCl Charlson comorbidity index, ECOG-PS Eastern Cooperative Oncology Group Performance Status

The incidence of respiratory complications such as atelectasis or pneumonia tended to increase with $\mathrm{CCI}$ score: $20.3 \%(n=12 / 59)$ in patients with a score of 0 , 9.2\% $(n=6 / 65)$ in patients with a score of $1,12.1 \%(n=$ $7 / 58)$ in patients with a score of $2,34.5 \%(n=10 / 29)$ in patients with a score of $3,39.1 \%(n=9 / 23)$ in patients with a score of 4 , and $12.5 \%(n=1 / 8)$ in patients with a score of 5 or more (Fig. 3). The incidence of atelectasis was $20 / 60(33.3 \%)$ in patients with a CCI score $\geq 3$ and $21 / 182(11.5 \%)$ in patients with a CCI score $<3(P<$ 0.01 ). Post-procedural pneumonia developed only in 4 


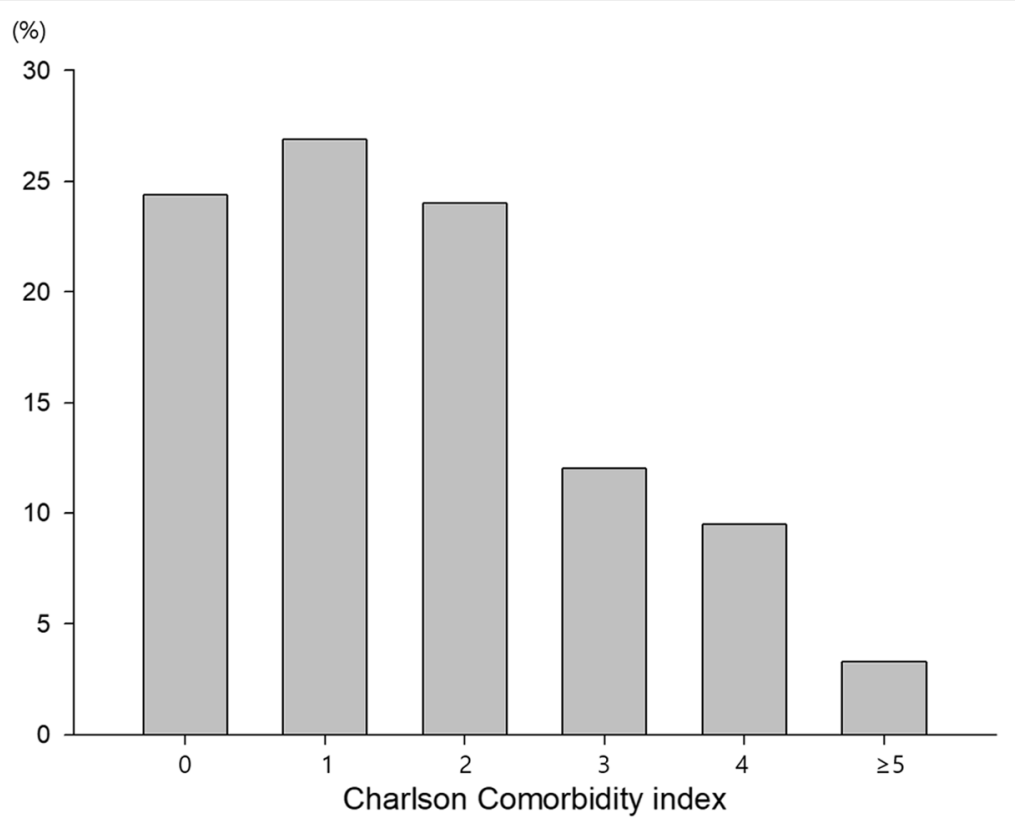

Fig. 1 Percentage of patients by $\mathrm{CCl}$ score

patients of $\mathrm{CCI}<3$. The incidence of respiratory complications (atelectasis or pneumonia) was higher in the group with a CCI score $\geq 3$ (Table 3 ).

Uni- and multivariate analyses showed that age and presence of a CCI score $\geq 3$ were related to the incidence of atelectasis or pneumonia after endoscopic resection in extremely elderly patients. The adjusted odds ratio for patients with a CCI score $\geq 3$ and the development of atelectasis or pneumonia was 3.103 (95\% CI, 1.5386.261, Table 4).

\section{Clinical outcomes}

En bloc resection was achieved in 90.5\% (219/242) of patients, while complete resection was achieved in $87.2 \%$ $(211 / 242)$ of patients. Among 31 patients with incomplete resection, $12.9 \%$ (4/31) patients underwent additional operation and 3.2\% (1/31) underwent additional endoscopic resection. There was no significant difference in the en bloc resection or complete resection rates between the patients with low and high CCI scores (Table $3)$. Tumor recurrence occurred in 3.8\% (8/211) patients with complete resection. .

\section{Discussion}

Our study demonstrated that: (1) endoscopic resection was effective and safe for extremely elderly ( $\geq 75$ years of age) patients with gastric neoplasms under careful consideration; and (2) age and higher CCI score $(\geq 3)$ were independent risk factors for atelectasis or pneumonia after endoscopic resection in extremely elderly patients.

Several studies have examined the treatment outcomes and safety of endoscopic resection in elderly patients, which showed no significant difference in treatment outcomes of endoscopic resection of EGC in elderly patients [4-6]. In our study including extremely elderly patients, the en bloc resection rate was $90.5 \%$ and the complete

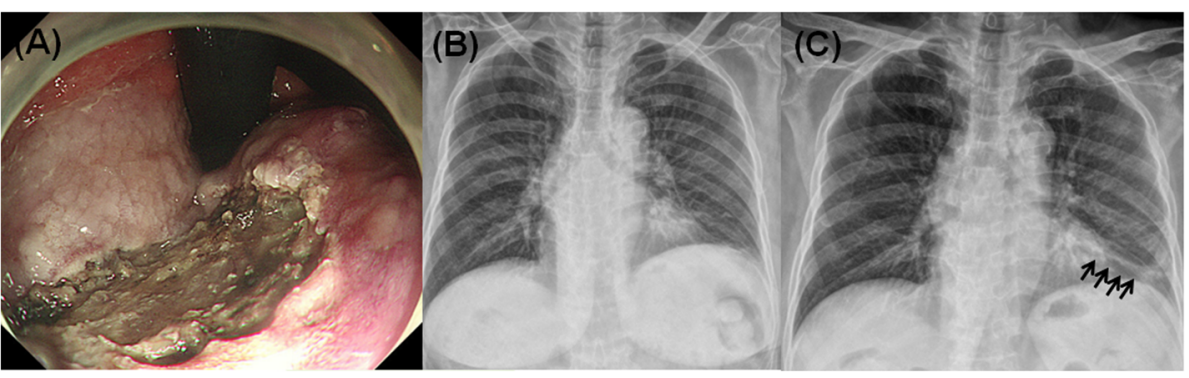

Fig. 2 One example of atelectasis in an elderly patient (patient aged 75 years over who underwent endoscopic submucosal dissection). Photo of procedure $\mathbf{a}$. X-ray before procedure $\mathbf{b}$ and $24 \mathrm{~h}$ after the procedure $\mathbf{c}$ 


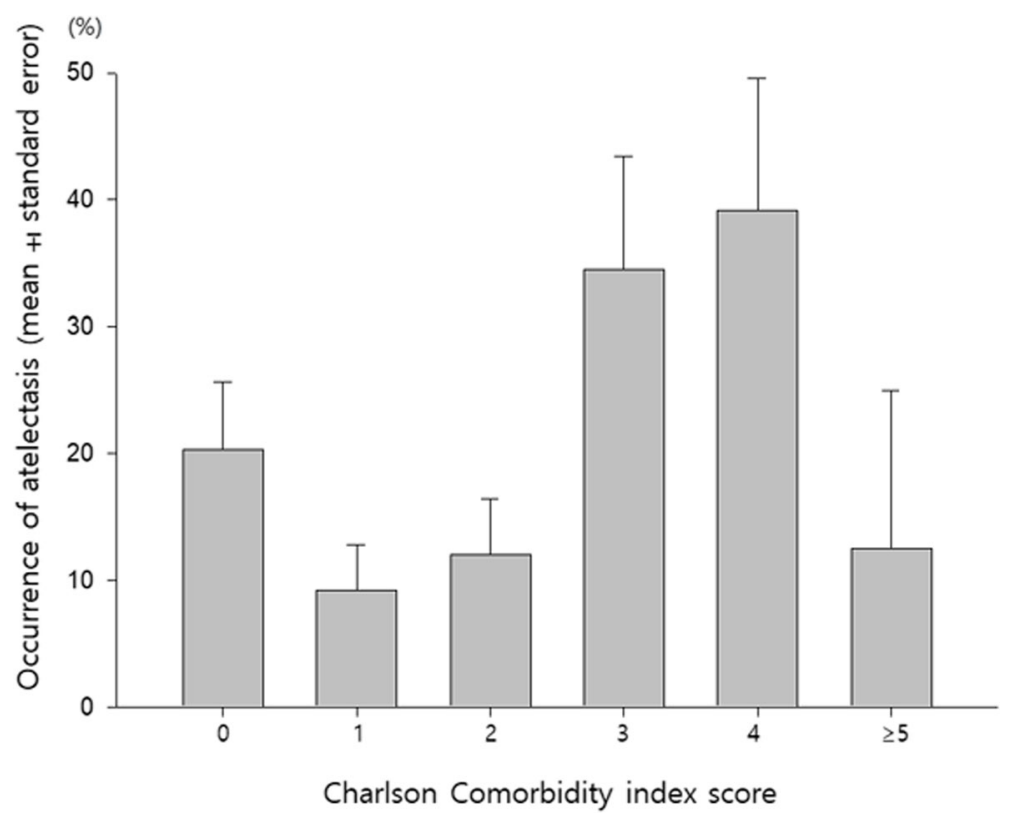

Fig. 3 Atelectasis occurrence by CCI score (Data are expressed as mean \pm standard error)

resection rate was $87.2 \%$, similar to the rates reported in previous studies $[4,7,20,21]$. Procedure-related bleeding and procedure-related perforation was observed in 4.9 and $0.4 \%$ of extreme elderly patients, respectively. These complication rates were comparable in those of other studies including elderly or non-elderly patients [7, 20]. Sedation-related complications such as intraprocedural hypotension and oxygen desaturation is known to be occurred more frequently in elderly patients [20, 22]. Furthermore, post-procedural respiratory complications such as atelectasis or pneumonia developed more frequently in elderly patients than in nonelderly patients $[7,20]$. Tokioka et al. demonstrated that recovery time from respiratory complications was longer and performance score was higher after endoscopic resection of EGC in patients aged 65 years and older [4]. In our study, significant hypoxemia occurred in $4.1 \%$ and post-procedural respiratory complications occurred in $18.6 \%$ (atelectasis in $16.9 \%$ and pneumonia in $1.7 \%$ ). Development of atelectasis in perioperative patients is associated with decreased lung compliance and increased pulmonary vascular resistance leading to lung injury and impairment of oxygenation [23]. Even though most patients with atelectasis recovered with conservative treatment in this study, persistent prolonged atelectasis after anesthesia is known to increase perioperative respiratory complications leading to significant consequence, especially in patients with underlying lung disease or cardiopulmonary dysfunction [23-26]. Therefore, early detection of atelectasis and effort for reversal of atelectasis in those patients may prevent significant periprocedural respiratory complication and improve clinical outcomes.

In recent studies, respiratory complication after endoscopic resection was found to be significantly related to the procedure time, the degree of sedation, and the amount of propofol use [27, 28]. In our study, respiratory complication tended to increase with increasing procedure time, but it was not statistically significant. In addition, there was no correlation between the use of propofol or the dose used, and an increase in respiratory complication.

Charlson et al. developed a scoring system to classify prognostic comorbidity and predict in-hospital and 1-year mortality rates [13]. Several studies reported that CCI predicted the prognosis of various diseases such as ischemic stroke [14], end-stage renal disease [15], cirrhosis [17], and lung cancer [29]. It could be adapted to patients in health care [30] and post-operative outcomes in acute cholecystitis [31]. In our study, CCI score was not related to procedure-related complications or immediate sedation-related complications such as hypoxemia or hypotension. However, postprocedural complications including atelectasis/pneumonia were frequently observed in extremely elderly patients with higher a CCI score $(\geq 3)$. Therefore, we expect to apply CCI score to other advanced endoscopic procedures including endoscopic retrograde cholangio-pancreatography, endoscopic ultrasonography-guided intervention, submucosal tunneling endoscopic resection or enteroscopy in elderly patients to evaluate the risk for periprocedural complications.

This study has several limitations; first, this study might not have included patients with very severe or uncontrolled comorbidities due to its retrospective design. 
Table 3 Treatment outcomes and complications by $\mathrm{CCl}$ score

\begin{tabular}{|c|c|c|c|}
\hline & $\mathrm{CCl}<3(n=182)$ & $\mathrm{CCl} \geq 3(n=60)$ & $P$ value \\
\hline Age, mean $\pm S D$ & $78.6 \pm 3.1$ & $79.0 \pm 3.3$ & 0.38 \\
\hline Sex (female) & $81(44.5)$ & $20(33.3)$ & 0.13 \\
\hline Procedure time, min, median (range) & $30(4 \sim 150)$ & $25(5 \sim 120)$ & 0.05 \\
\hline \multicolumn{4}{|l|}{ Resectability, $n(\%)$} \\
\hline En bloc resection & $161(88.5)$ & $58(96.7)$ & \multirow[t]{2}{*}{0.06} \\
\hline Piecemeal resection & $21(11.5)$ & $2(3.3)$ & \\
\hline \multicolumn{4}{|l|}{ Method of sedation, $n(\%)$} \\
\hline Midazolam + Pethidine + Propofol & $160(87.9)$ & $55(91.7)$ & \multirow[t]{2}{*}{0.42} \\
\hline Midazolam + Pethidine & $22(12.1)$ & $5(8.3)$ & \\
\hline \multicolumn{4}{|l|}{ Dose of sedative agents, mean \pm SD } \\
\hline Midazolam, mg & $3.65 \pm 0.95$ & $3.39 \pm 0.87$ & 0.07 \\
\hline Propofol, mg & $126.4 \pm 79.2$ & $132.6 \pm 92.5$ & 0.64 \\
\hline \multicolumn{4}{|l|}{ Procedure-related complications, $n$ (\%) } \\
\hline Immediate bleeding & $10(5.5)$ & 0 & 0.06 \\
\hline Delayed bleeding & $2(1.1)$ & 0 & 0.42 \\
\hline Perforation & $3(1.6)$ & 0 & 0.32 \\
\hline \multicolumn{4}{|l|}{ Sedation-related complications, n (\%) } \\
\hline \multicolumn{4}{|l|}{ Immediate complication } \\
\hline Hypotension & $1(0.5)$ & 0 & 0.57 \\
\hline Arrhythmia & $37(20.3)$ & $14(23.3)$ & 0.62 \\
\hline Hypoxia & $8(4.4)$ & $2(3.3)$ & 0.72 \\
\hline Hypopnea or apnea & $1(0.5)$ & 0 & 0.57 \\
\hline \multicolumn{4}{|l|}{ Delayed complication } \\
\hline Atelectasis & $21(11.5)$ & $20(33.3)$ & $<0.01$ \\
\hline Pneumonia & $4(2.2)$ & $0(0)$ & 0.25 \\
\hline Atelectasis or Pneumonia & $25(13.7)$ & $20(33.3)$ & $<0.01$ \\
\hline
\end{tabular}

CCl Charlson comorbidity index

All enrolled patients could be selected since they were considered suitable candidates for endoscopic therapy by the endoscopist. However, it is not possible to design a prospective study that enrolls only patients with severe morbidities due to ethical concerns. Second, we could not get the information for effect of sedative agents, as clinician choose the sedative agents for the procedure according to risk assessment of procedural complication.

\section{Conclusions}

In conclusion, although endoscopic resection is considered safe and effective for elderly patients, endoscopists must perform it cautiously, particularly in extremely elderly patients with a high CCI score, to prevent post-procedural respiratory complications such as pneumonia or atelectasis. In the future, we need to conduct a study to prevent postprocedural respiratory complication.

Table 4 Univariate and multivariate analysis for predicting atelectasis/pneumonia after endoscopic resection in elderly patients

\begin{tabular}{llll}
\hline Variables & COR $(95 \% \mathrm{Cl})$ & $P$ value & aOR $(95 \% \mathrm{Cl})$ \\
\hline Age, yrs & $1.175(1.065-1.296)$ & 0.001 & $1.173(1.061-1.297)$ \\
Sex (female) & $0.781(0.408-1.498)$ & 0.458 & \\
Body mass index, $\mathrm{kg} / \mathrm{m}^{2}$ & $0.999(0.904-1.105)$ & 0.987 & \\
$\mathrm{CCl} \geq 3$ & $3.140(1.586-6.215)$ & 0.001 & $3.103(1.538-6.261)$ \\
Use of propofol & $0.738(0.242-2.251)$ & 0.593 & \\
Procedure time, min & $1.012(1.000-1.025)$ & 0.056 & \\
\hline
\end{tabular}

COR crude odds ratio, $a O R$ adjusted $\mathrm{OR}, \mathrm{CCl}$ Charlson comorbidity index 


\section{Acknowledgements}

No

\section{Authors' contributions}

All authors have read and approved this manuscript. Sunmin Kim. analysis of electronic medical records; drafting of the manuscript. Dong Hyun Kim: study concept and design; analysis of electronic medical records; drafting of the manuscript. Seon-Young Park: study concept and design; data analysis and interpretation; drafting and finalization of the manuscript; study supervision. Chang Hwan Park, Hyun Soo Kim, Sung Kyu Choi and Jong Sun Rew: patient recruitment and care.

\section{Funding}

This study was supported by the Chonnam National University Hospital Research Institute of Clinical Medicine (CRI 14011-1 and B2019-1047). This funding source had no role in the design of this study and collection, analysis and interpretation of data and in writing the manuscript.

\section{Availability of data and materials}

The datasets used and/or analyzed during the current study available from the corresponding author on request.

\section{Ethics approval and consent to participate}

Ethics Committee of the Chonnam National University Hospital approved this current study. CNUH-2018-236).

\section{Consent for publication}

Not Applicable.

\section{Competing interests}

The authors have no conflicts of interests.

\section{Received: 24 October 2019 Accepted: 30 June 2020}

Published online: 09 July 2020

\section{References}

1. Oka S, Tanaka S, Kaneko I, Mouri R, Hirata M, Kawamura T, Yoshihara M, Chayama K. Advantage of endoscopic submucosal dissection compared with EMR for early gastric cancer. Gastrointest Endosc. 2006;64(6):877-83.

2. Takeuchi $Y$, Uedo N, lishi H, Yamamoto S, Yamamoto S, Yamada T, Higashino K, Ishihara R, Tatsuta M, Ishiguro S. Endoscopic submucosal dissection with insulated-tip knife for large mucosal early gastric cancer: a feasibility study (with videos). Gastrointest Endosc. 2007;66(1):186-93.

3. Oda I, Gotoda T, Hamanaka H, Eguchi T, Saito Y, Matsuda T, Bhandari P, Emura F, Saito D, Ono H. Endoscopic submucosal dissection for early gastric cancer: technical feasibility, operation time and complications from a large consecutive series. Dig Endosc. 2005;17(1):54-8.

4. Tokioka S, Umegaki E, Murano M, Takeuchi N, Takeuchi T, Kawakami K, Yoda Y, Kojima Y, Higuchi K. Utility and problems of endoscopic submucosal dissection for early gastric cancer in elderly patients. J Gastroenterol Hepatol. 2012;27(Suppl 3):63-9.

5. Kakushima N, Fujishiro M, Kodashima S, Muraki Y, Tateishi A, Yahagi N, Omata M. Technical feasibility of endoscopic submucosal dissection for gastric neoplasms in the elderly Japanese population. J Gastroenterol Hepatol. 2007;22(3):311-4.

6. Hirasaki S, Tanimizu M, Nasu J, Shinji T, Koide N. Treatment of elderly patients with early gastric cancer by endoscopic submucosal dissection using an insulated-tip diathermic knife. Intern Med. 2005:44(10):1033-8.

7. Isomoto H, Ohnita K, Yamaguchi N, Fukuda E, Ikeda K, Nishiyama H, Akiyama M, Ozawa E, Nakao K, Kohno S, et al. Clinical outcomes of endoscopic submucosal dissection in elderly patients with early gastric cancer. Eur J Gastroenterol Hepatol. 2010;22(3):311-7.

8. Zhang Y, Huang L, Li L, Ji F. Endoscopic submucosal dissection for early gastric neoplasms in elderly patients. J Laparoendosc Adv Surg Tech A. 2014;24(6):391-8.

9. From the Centers for Disease Control and Prevention. Public health and aging: trends in aging--United States and worldwide. JAMA. 2003;289(11): 1371-3.

10. Fried L, Barron J. In: Handbook of Urban Health: Chapter 9. Older Adults; 2005. p. 177-99.
11. Quine MA, Bell GD, McCloy RF, Charlton JE, Devlin HB, Hopkins A. Prospective audit of upper gastrointestinal endoscopy in two regions of England: safety, staffing, and sedation methods. Gut. 1995;36(3):462-7.

12. McLernon DJ, Donnan PT, Crozier A, Dillon J, Mowat C. A study of the safety of current gastrointestinal endoscopy (EGD). Endoscopy. 2007;39(8):692-700.

13. Charlson ME, Pompei $P$, Ales $K L$, MacKenzie CR. A new method of classifying prognostic comorbidity in longitudinal studies: development and validation. J Chronic Dis. 1987:40(5):373-83.

14. Goldstein LB, Samsa GP, Matchar DB, Horner RD. Charlson index comorbidity adjustment for ischemic stroke outcome studies. Stroke. 2004; 35(8):1941-5.

15. Hemmelgarn BR, Manns BJ, Quan H, Ghali WA. Adapting the Charlson comorbidity index for use in patients with ESRD. Am J Kidney Dis. 2003; 42(1):125-32.

16. Lee DS, Donovan L, Austin PC, Gong Y, Liu PP, Rouleau JL, Tu JV. Comparison of coding of heart failure and comorbidities in administrative and clinical data for use in outcomes research. Med Care. 2005;43(2):182-8.

17. Myers RP, Quan H, Hubbard JN, Shaheen AA, Kaplan GG. Predicting inhospital mortality in patients with cirrhosis: results differ across risk adjustment methods. Hepatology. 2009;49(2):568-77.

18. Eisen GM, Baron TH, Dominitz JA, Faigel DO, Goldstein JL, Johanson JF, Mallery JS, Raddawi HM, Vargo JJ 2nd, Waring JP, et al. Guideline on the management of anticoagulation and antiplatelet therapy for endoscopic procedures. Gastrointest Endosc. 2002;55(7):775-9.

19. Early DS, Lightdale JR, Vargo JJ 2nd, Acosta RD, Chandrasekhara V, Chathadi KV, Evans JA, Fisher DA, Fonkalsrud L, Hwang JH, et al. Guidelines for sedation and anesthesia in Gl endoscopy. Gastrointest Endosc. 2018;87(2): 327-37

20. Yang TC, Hou MC, Chen PH, Hsin IF, Chen LK, Tsou MY, Lin HC, Lee FY. Clinical outcomes and complications of endoscopic submucosal dissection for superficial gastric neoplasms in the elderly. Medicine (Baltimore). 2015; 94(44):e1964.

21. Kim SY, Sung JK, Moon HS, Kim KS, Jung IS, Yoon BY, Kim BH, Ko KH, Jeong $\mathrm{HY}$. Is endoscopic mucosal resection a sufficient treatment for low-grade gastric epithelial dysplasia? Gut Liver. 6(4):446-51.

22. Chinda D, Sasaki Y, Tatsuta T, Tsushima K, Wada T, Shimoyama T, Fukuda S. Perioperative complications of endoscopic submucosal dissection for early gastric cancer in elderly Japanese patients 75 years of age or older. Intern Med. 2015;54(3):267-72.

23. Duggan M, Kavanagh BP. Atelectasis in the perioperative patient. Curr Opin Anaesthesiol. 2007;20(1):37-42

24. Ray K, Bodenham A, Paramasivam E. Pulmonary atelectasis in anaesthesia and critical care. Cont Educ Anaesth Crit Care Pain. 2013;14(5):236-45.

25. Restrepo RD, Braverman J. Current challenges in the recognition, prevention and treatment of perioperative pulmonary atelectasis. Expert Rev Respir Med. 2015;9(1):97-107.

26. Tusman G, Böhm SH, Warner DO, Sprung J. Atelectasis and perioperative pulmonary complications in high-risk patients. Curr Opin Anaesthesiol. 2012; 25(1):1-10.

27. Choe JW, Jung SW, Song JK, Shim E, Choo JY, Kim SY, Hyun JJ, Koo JS, Yim $\mathrm{HJ}$, Lee SW. Predictive factors of atelectasis following endoscopic resection. Dig Dis Sci. 2016;61(1):181-8.

28. Park CH, Kim H, Kang YA, Cho IR, Kim B, Heo SJ, Shin S, Lee H, Park JC, Shin SK, et al. Risk factors and prognosis of pulmonary complications after endoscopic submucosal dissection for gastric neoplasia. Dig Dis Sci. 2013; 58(2):540-6.

29. Yang CC, Fong Y, Lin LC, Que J, Ting WC, Chang CL, Wu HM, Ho CH, Wang JJ, Huang $\mathrm{Cl}$. The age-adjusted Charlson comorbidity index is a better predictor of survival in operated lung cancer patients than the Charlson and Elixhauser comorbidity indices. Eur J Cardio Thor Surg. 2018;53(1):235-40.

30. Bannay A, Chaignot C, Blotiere PO, Basson M, Weill A, Ricordeau P, Alla F. The best use of the Charlson comorbidity index with electronic health care database to predict mortality. Med Care. 2016;54(2):188-94.

31. Bonaventura A, Leale I, Carbone F, Liberale L, Dallegri F, Montecucco F, Borgonovo G. Pre-surgery age-adjusted Charlson comorbidity index is associated with worse outcomes in acute cholecystitis. Digest Liver Dis. 2019;51(6):858-63.

\section{Publisher's Note}

Springer Nature remains neutral with regard to jurisdictional claims in published maps and institutional affiliations. 